\title{
Selective Modification of Chitosan to Enable the Formation of Chitosan-DNA Condensates by Electron Donator Stabilization
}

\author{
Karl E. Kador and Anuradha Subramanian \\ Department of Chemical and Biomolecular Engineering, University of Nebraska, Lincoln, 207 Othmer Hall, Lincoln, \\ NE 68588-0643, USA \\ Correspondence should be addressed to Anuradha Subramanian, asubramanian2@unl.edu
}

Received 2 February 2011; Revised 4 May 2011; Accepted 31 May 2011

Academic Editor: José das Neves

Copyright ( $\odot 2011$ K. E. Kador and A. Subramanian. This is an open access article distributed under the Creative Commons Attribution License, which permits unrestricted use, distribution, and reproduction in any medium, provided the original work is properly cited.

\begin{abstract}
Chitosan, a polyaminosaccharide, has been investigated for its use in the field of drug-delivery and biomaterial applications because of its natural biocompatibility and polycationic properties. Chemical modifications of chitosan have been attempted in an effort to increase the transfection efficiency with respect to gene delivery applications; however, it is unknown how these modifications affect the formation of the condensates. This study attempts to determine the effects of modification of the cationic center of chitosan on the ability to condense DNA. Specifically, electron-donating or -withdrawing groups were used as modifiers of the cationic charge on the chitosan backbone to stabilize the protonated form of chitosan, which is necessary to form condensates and increase the efficiency of the polymer to condense DNA by yielding condensates at a lower nitrogen to phosphorous $(\mathrm{N}: \mathrm{P})$ ratio. While an $\mathrm{N}$ : P ratio of 7 is needed to condense DNA with unmodified chitosan, phthalate-modified chitosan yielded condensates were obtained at an $\mathrm{N}: \mathrm{P}$ ratio of 1.0.
\end{abstract}

\section{Introduction}

A natural polymer that has received increased research attention because of its inherent biocompatibility is chitin and its deacetylated derivative, chitosan $[\beta(1-4)-2$ amino-2-deoxyD-glucose] $[1,2]$. Depending on the degree of deacetylation, chitosan is a copolymer of N-acetyl-D-glucosamine and glucosamine units, with the glucosamine units predominating [3-5]. Due to its good biological activity, relative ease of solubility, biocompatibility, and biodegradability, chitosan and its derivatives have attracted attention as potential applicants in the field of biomedical polymers $[3,6,7]$. Additionally, the $\mathrm{pH}$-dependent solubility of chitosan provides a convenient mechanism for processing under mild conditions and the high charge density of chitosan in solution allows for chitosan to form insoluble ionic complexes with a wide variety of water soluble polyanionic species, thus allowing for facile substitutions [8].

Chitosan and modified chitosans find a variety of applications in biomedical applications, including biomaterials for use in tissue engineering and drug delivery systems, and in bioseparation applications, including nano- and macro scale separations, and classical affinity- and nonaffinitybased chromatographic systems $[2,6,7,9-16]$. Specifically in the area of targeted delivery, chitosan-based particles have been extensively investigated for the delivery of DNA macromolecules, proteins, peptides, and drugs [4, 17-19]. The abundance of literature to form chitosan particles with protein loadings is extensive and, generally speaking proteins are physically entrapped in chitosan chains to allow a latter release. However, in applications that seek to form chitosanDNA nano- or microparticles with an intended application in gene therapy or gene transfection applications, there are three areas which must be optimized before it can be used effectively. First, effective loading of the DNA to the polymer must be achieved. Second, particles must be able to target specific cells within the body. Third, the particles must be able to effectively diffuse through or be actively transported across the cell membrane. As one might expect, all three of these areas are interrelated because of the polymer being used as the carrier agent is involved in all three steps. However, for research purposes, it is best to study each of these three areas 
separately, to understand the principles behind each step so that the overall problem can be addressed. It is from this standpoint that this research project has been designed.

Chitosan-DNA polymer complexes are commonly attained via a condensation reaction, where the protonated amine $(\mathrm{N})$ of chitosan forms an ionic attraction to the phosphate groups (P) found in the backbone of DNA; thus inducing a charge-induced titration leading to DNA condensation [19-23]. This charge-induced condensation is postulated to be influenced by the physical characteristics of the chitosan polymer as well as the experimental conditions. For example, the molecular weight of chitosan used was noted to have a minimal effect on the percentage of DNA bound by the polymer $[24,25]$; whereas the degree of deacetylation (DA) of chitosan was shown to impact the $\mathrm{N}: \mathrm{P}$ ratio required for the complete condensation of DNA $[26,27]$. In this study, an $\mathrm{N}$ : P ratio of 9 was needed to yield DNA condensates when chitosan with a $62 \%$ DA was used, and $\mathrm{N}: \mathrm{P}$ ratio of 3 was shown to yield DNA condensates with $90 \%$ DA chitosan. AFM analyses of polyplexes made from mixing plasmid DNA with chitosan were noted to yield a blend of toroids and rods, more toroids then rods were observed with higher DA chitosans and the amount of chitosan required to fully compact DNA into well-defined toroidal and rodlike structures was found to be strongly dependent on the chitosan molecular weight, and thus its total charge [22].

In this paper, we are interested in understanding and optimizing the structure-property correlations between chemical modification of the chitosan and the resultant biological activity, in charge titrating negatively charged biomolecules, for example, condensation of DNA. This study will attempt to determine the effects of modification of the cationic center of chitosan on the ability to condense DNA. The underlying hypothesis is that the use of electron donating or withdrawing groups as modifiers of the cationic charge on a polymer will lead to a more efficient condensation vehicle by stabilizing the ionization of the polymer. The study will look at two classes of modifications and its impact on DNA condensation, where the primary nitrogen on the chitosan backbone will be modified with groups that impart electron-donating or electron-withdrawing attributes. The overall strategy for the modification of the chitosan backbone is outlined in Figures 1 and 2. This paper will also seek to evaluate the effect of steric hindrance on the condensation of DNA.

\section{Material and Methods}

All chemicals were of analytical-grade or better. Chitosan with various degrees of deacetylation were purchased from Vanson Halosource (Remmond, WA, USA). In this study, chitosan with $81.7 \%$ of deacetylation $(276 \mathrm{kDa}$, Lot \# 01CISQ-1702) was used in all experiments without further purification. All materials were purchased from SigmaAldrich Inc. (St. Louis, MO) and were of the highest purity available unless otherwise noted. All methods described are the final optimized method for production.

\section{Modifications of Chitosan}

3.1. Methyl Addition to Chitosan. This procedure was adapted from the procedure detailed by Cignarella et al. [28] and is schematically represented in Figure 1, reaction 1. Briefly, 1.68 grams of $92.1 \%$ DA chitosan was dissolved into $75 \mathrm{~mL}$ of formic acid in a 3-neck $250 \mathrm{~mL}$ round bottom flask with a reflux attached. The solution was heated under an inert atmosphere to $110^{\circ} \mathrm{C}$. $1.1 \mathrm{~mL}$ of $37 \%$ formaldehyde was added via syringe and the solution was stirred at temperature for 3 hours. The solution was allowed to equilibrate to room temperature and then evaporated under reduced pressure to remove the excess acid. The resulting solid was neutralized using $5 \mathrm{~N}$ sodium hydroxide. The solid precipitate was collected by centrifugation and washed 3 times with distilled water. The final solid was frozen at $-80^{\circ} \mathrm{C}$ and lyophilized for at least 8 hours. The dry product was then analyzed by infrared spectroscopy.

3.2. Alcohol Addition to Chitosan. This procedure is based upon that described in Vogel's Textbook of Practical Organic Chemistry [29] and is schematically represented in Figure 1, reaction 2. Briefly, 1.68 grams of $92.1 \%$ DA chitosan was placed in a 3 neck round bottom flask with reflux attached and reduced to $0^{\circ} \mathrm{C}$. $10 \mathrm{~mL}$ of $0.2 \mathrm{M}$ hyperchloric acid (bleach, Clorox Company, Oakland, CA) was added with stirring. After 10 minutes, $4.5 \mathrm{~mL}$ tetrahydrofuran and $5.5 \mathrm{~mL}$ of a $1.8 \mathrm{M}$ borane-tetrahydrofuran solution was added allowed to react for 1.5 hours while the mixture equilibrated to room temperature. $2 \mathrm{~mL}$ of $5 \mathrm{M}$ sodium hydroxide was added to the reaction mixture and allowed to react for 5 minutes. A 20\% theoretical mole excess of 20\% hydrogen peroxide solution (Fluka, Buchs, SG, Sitzerland) was added very slowly to the reaction producing a very fast and violent reaction. The solid particles were collected by centrifugation and washed 3 times with distilled water. The final solid was frozen and lyophilized for at least 8 hours. The dry product was then analyzed by infrared spectroscopy.

3.3. Chlorine Addition to Chitosan. This procedure is based upon that used by Favreau et al. [30] and is schematically represented in Figure 1, reaction 3. Briefly, $200 \mathrm{~mL}$ of $0.2 \mathrm{M}$ hyperchloric acid (bleach) was cooled to $0^{\circ} \mathrm{C}$. 3.4 grams of 92.1\% DA chitosan was added and reacted with stirring for 3 hours. The mixture was separated by centrifugation at $4^{\circ} \mathrm{C}$. The solid was collected and washed 3 times with chilled distilled water. The final solid was frozen and lyophilized for at least 8 hours. The dry product was then analyzed by infrared spectroscopy.

3.4. Cyclohexane Addition to Chitosan. This procedure is based upon that used by Kabalka and Wang [31] and is schematically represented in Figure 2, reaction 4. Briefly, $3.35 \mathrm{~mL}$ cyclohexene was added to $10 \mathrm{~mL}$ tetrahydrofuran with stirring and cooled to $0^{\circ} \mathrm{C}$. $5.5 \mathrm{~mL}$ of hydroborane in THF was added at temperature and allowed to react under an inert atmosphere for 3.5 hours. In a separate flask, $1.68 \mathrm{~g}$ of $92.1 \%$ DA chitosan was cooled to $0^{\circ} \mathrm{C}$. $10 \mathrm{~mL}$ of $2 \mathrm{M}$ 
Reaction 1: neutral group addition<smiles>NC1COC(CO)C(O)C1O</smiles><smiles>O=CO</smiles><smiles>CNC1COC(CO)C(O)C1O</smiles>

Reaction 4: steric hindering, neutral group addition<smiles>NC1COC(CO)C(O)C1O[AsH3]O</smiles><smiles>OCC1OCC(NC2CCCCC2)C(O)C1O</smiles>

Reaction 2: electron donating group addition<smiles>NC1COC(CO)C(O)C1O</smiles><smiles>OCC1OCC(NO)C(O)C1O</smiles>

Reaction 3: electron withdrawing group addition<smiles>NC1COC(CO)C(O)C1O</smiles>

FIGURE 1: Proposed chemical modifications to chitosan. Reaction 1: methyl-group addition to chitosan, reaction 2: alcohol-group addition to chitosan, reaction 6: chlorine-group addition to chitosan.

hyperchloric acid was added dropwise with mixing. This reaction was allowed to proceed under inert atmosphere for 5 minutes. The complexed hydroborane was transferred via a double-sided needle to the flask containing the chlorinated chitosan. After transfer and initial mixing, the solution was allowed to warm to room temperature but maintained under an inert atmosphere and proceeded for 1 hour. After reaction the solution was decanted from the solid phase. The solid was transferred using a $2 \%$ solution of acetic acid and neutralized using $1 \mathrm{M}$ sodium hydroxide. The solid was collected by centrifugation and washed 3 times with distilled water. The solid product was then frozen and lyophilized for at least 8 hours. The dry product was then analyzed by infrared spectroscopy.

3.5. Benzene Addition to Chitosan. This procedure is based upon that used by Ozaki and Akihiro [32] and is schematically represented in Figure 2, reaction 5. Briefly, $0.0183 \mathrm{mols}$ of $92.1 \%$ DA chitosan was added to 0.055 mols cyclohexene
Reaction 5: steric hindering, electron donating group addition<smiles>NC1COC(CO)C(O)C1O</smiles>

Reaction 6: steric hindering, electron withdrawing group addition<smiles>CC(Cl)C(C)C(=O)N1C(=O)c2ccccc2C1=O</smiles>

Figure 2: Proposed steric hindering chemical modifications to chitosan. Reaction 4: cyclohexane addition to chitosan, reaction 5: benzene addition to chitosan and reaction 6 phthalate group addition to chitosan.

and $0.56 \mathrm{mmols}$ palladium (II) chloride. The mixture was heated to $60^{\circ} \mathrm{C}$ with reflux and reacted under an inert atmosphere with stirring. After 23 hours, the atmosphere was changed to a $5 \%$ mix of hydrogen/inert gas and reacted for three hours. The solid product was washed three times with distilled water and collected centrifugation. The solid product was frozen and lyophilized for at least 8 hours. The dry product was analyzed by infrared spectroscopy.

3.6. Phthalate Addition to Chitosan. This procedure is based upon that described in Vogel's Textbook of Practical Organic Chemistry [29] and is schematically represented in Figure 2, reaction 6. Briefly, 3 grams of $92.1 \%$ DA chitosan was added 
to $150 \mathrm{~mL}$ of chloroform in a 3-neck $250 \mathrm{~mL}$ round bottom flask with a reflux attached. The mixture was heated to $70^{\circ} \mathrm{C}$ with stirring under an inert atmosphere. At temperature, 3 grams phthalic acid anhydride was added and reacted for 25 minutes. The mixture was allowed to cool to room temperature, and the solution evaporated under reduced pressure. The solid remaining was washed with a $2 \%$ acetic acid solution twice to remove unmodified chitosan. The residual solid was washed with $1 \mathrm{M}$ sodium hydroxide to neutralize and collected by centrifugation. The solid was then washed three times with distilled water. The solid was frozen and lyophilized for at least 8 hours. The dry product was analyzed by infrared spectroscopy.

\section{Analysis of Modification}

4.1. Qualitative Analysis by Infrared Spectroscopy. Solid products were pressed into $2.5 \mathrm{~cm}$ diameter plates in a $1: 10$ ratio with analytical grade potassium bromide under 3 metric tons of pressure. The samples were analyzed by 100 scans from 600 to $3500 \mathrm{~cm}^{-1}$ with a $4 \mathrm{~cm}^{-1}$ resolution using either a Nicolete 20SXB FT-IR Spectrometer or a Nicolete 510P FTIR Spectrophotometer.

4.2. Quantitative Analysis by Ninhydrin. This procedure is based upon that described by Curotto and Aros [33]. Solid samples and D-glucosamine were dissolved separately in $2 \%$ acetic acid at a concentration of $0.1 \mathrm{mg} / \mathrm{mL}$. Different volumes of each sample $(0.1-0.5 \mathrm{~mL})$ were fractionated and to each $0.5 \mathrm{~mL} 4 \mathrm{M}$ acetic acid/acetate buffer at $\mathrm{pH} 5.5$ was added. The samples were brought to a $1 \mathrm{~mL}$ total volume using deionized water. $0.35 \mathrm{~g}$ of ninhydrin (Fluka) was dissolved in $100 \mathrm{~mL}$ of 200 proof ethanol. $2 \mathrm{~mL}$ of the ninhydrin solution was added to each $1 \mathrm{~mL}$ sample followed by heating at $90^{\circ} \mathrm{C}$ for 15 minutes. The samples absorbance was immediately taken following heating at a wavelength of $570 \mathrm{~nm}$ using a UV-Vis spectrophotometer. The absorbance for each sample was plotted as a function of concentration. The slope for each sample was calculated using a linear regression. The slope of each sample was then divided by the slope generated by D-glucosamine to give the concentration of free amine groups. The percent modification was determined by calculating the actual number of free amine groups of the sample and the total number of amine groups based upon the molecular weight of chitosan and the respective modification.

\section{Production and Purification of DNA Plasmid}

Plasmid DNA was supplied by the Biological Process and Development Facility at the University of Nebraska. The plasmid was transfected and grown in a E. coli culture for 2 days at $37^{\circ} \mathrm{C}$. The cells were separated, lysed, and purified using a Qiagen Plasmid DNA Maxi Kit (Qiagen, Valencia, CA) preparation. The resultant DNA was quantitated by UV-Vis spectroscopy at $260 \mathrm{~nm}$ and by fluorescence using the fluorescent binding agent Pico Green (Molecular Probes, Inc., Eugene, OR).

\section{Condensate Production and Characterization}

6.1. Production of DNA-Polymer Condensates. The procedure was based upon that described by Leong et al. [34] and Mao et al. [17]. Approximately 1 gram of chitosan or modified chitosan products were dissolved in $10 \mathrm{~mL}$ of a $2 \%$ acetic acid solution. Any solid remainder was centrifuged out of the solution and dried under vacuum to determine the actual mass in solution. The solution was then diluted to $250 \mathrm{~mL}$, and the total acetate concentration was adjusted to $25 \mathrm{mM}$ using sodium acetate. These solutions were then mixed with $10 \mu \mathrm{g}$ of either plasmid or Lambda DNA at a calculated Nitrogen: Phosphate ratio of $0.1,1,2,5$, or 7 . The mixture was adjusted to $500 \mu \mathrm{L}$ using $25 \mathrm{mM}$ sodium acetate solution to maintain the same salt concentration for all experiments. The final mixtures were vortexed for 15 seconds and allowed to react for 1 hour at $4^{\circ} \mathrm{C}$.

6.2. Quantitative Analysis of DNA Loading of the Condensates. DNA-Polymer condensates were prepared as described above. After production, the condensates were separated from noncomplexed DNA by centrifugation at $16 \times \mathrm{g}$ for 1 hour. Supernatant solutions were collected and a portion reacted with Pico Green fluorescent dye. The DNA from each sample was standardized to a sample with $10 \mu \mathrm{g}$ of DNA in $25 \mathrm{mM}$ and a tube with $25 \mathrm{mM}$ sodium acetate and no DNA. The loading was calculated from the mass balance.

6.3. Electrophoresis of DNA-Polymer Condensates. The DNApolymer condensates were separated from plasmid DNA by a centrifugation of $6 \times \mathrm{g}$ for 15 minutes. The supernatant was removed and discarded. The particles were resuspended in $250 \mu \mathrm{L}$ of $25 \mathrm{mM}$ sodium acetate solution. $10 \mu \mathrm{L}$ of the resuspended particles were removed and added to $2 \mu \mathrm{L}$ of a loading dye. The samples run for 2 hours in a $0.5 \%$ agarose gel which had been prepared with ethidium bromide. Agarose gels were developed under UV light.

6.4. Zeta Potential Analysis of Condensates. For this experiment, all stock solutions were filtered through a $0.22 \mu \mathrm{m}$ pore size filter. DNA-polymer condensates were prepared as described above except that lambda DNA was used. The condensates were separated from uncondensed DNA by a centrifugation of $6 \times \mathrm{g}$ for 15 minutes. The supernatant was removed and discarded. The particles were resuspended in $500 \mu \mathrm{L}$ of $25 \mathrm{mM}$ sodium acetate solution. The solution was diluted at a rate of $1: 10$ with deionized water. The samples were analyzed for zeta potential using a Zeta Plus zeta potential analyzer (Brookhaven Instruments Corp.).

\section{Results}

The number average molecular weight of the unmodified and modified chitosan samples used in this study was determined by gel permeation chromatography with internal standards ranging from 59 to $788 \mathrm{kDa}$. In certain cases, the molecular mass of the unmodified chitosan was also estimated using the experimentally determined intrinsic 


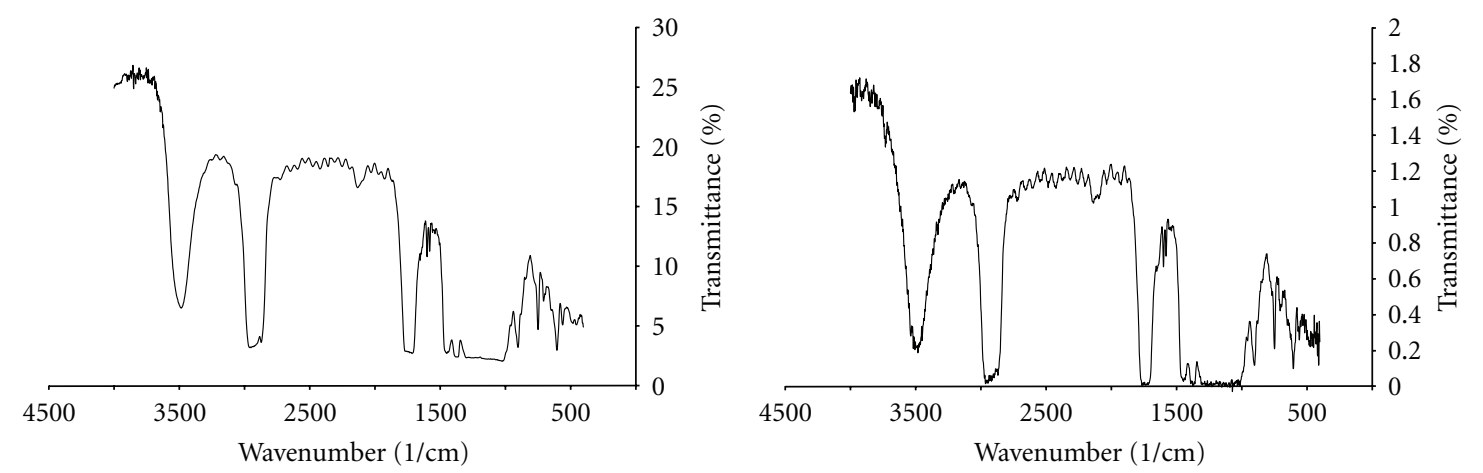

(a)

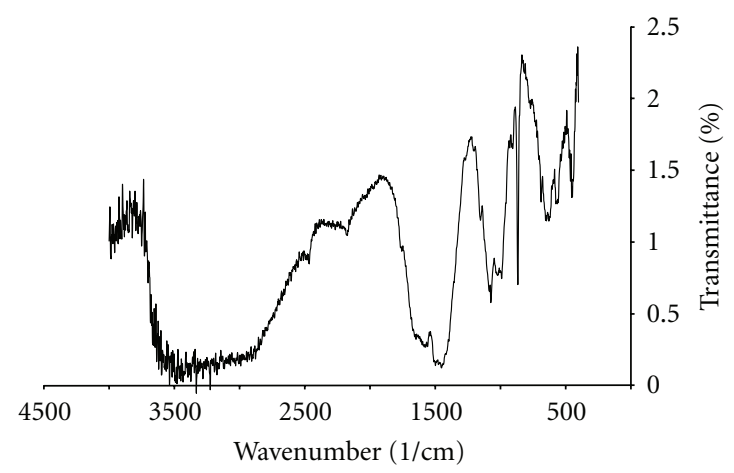

(c)

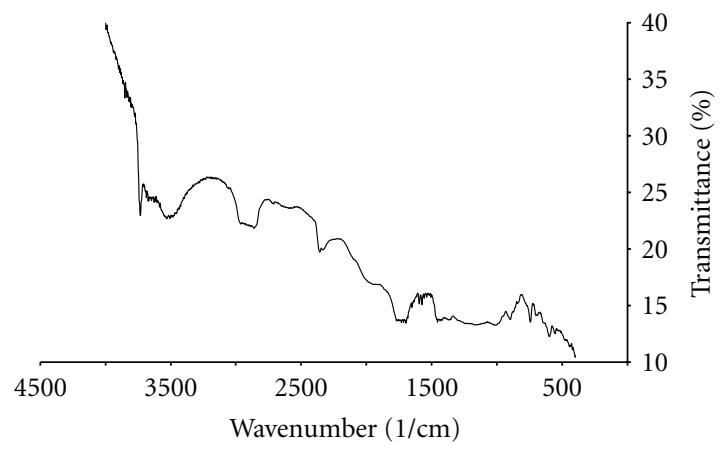

(e) (b)

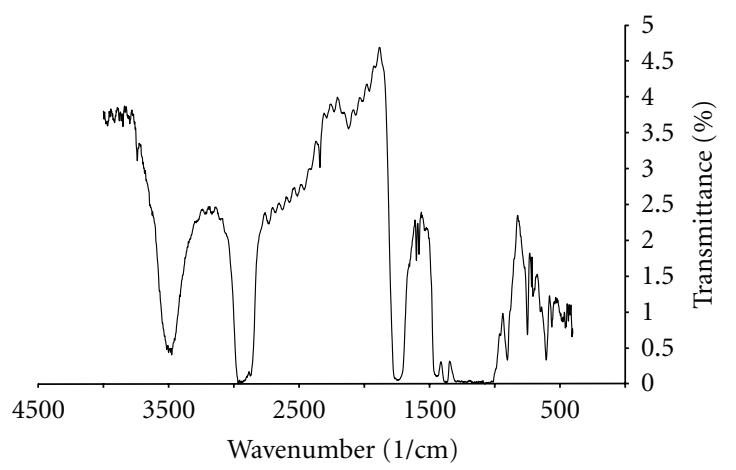

(d)

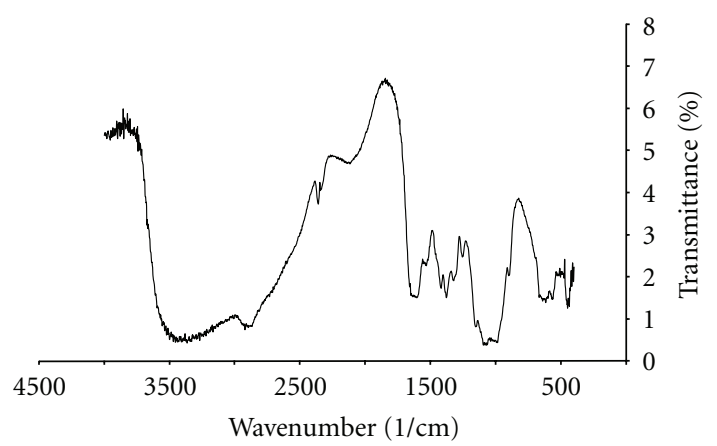

(f)

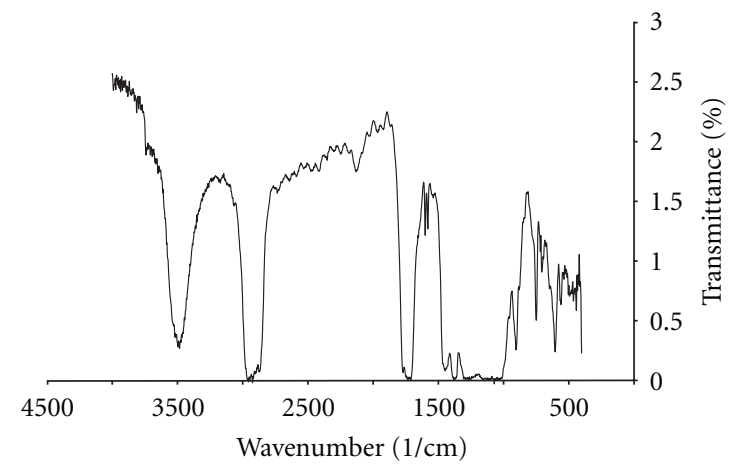

(g)

FIGURE 3: FTIR spectra (\% transmittance) of unmodified and modified chitosan. (a) Unmodified chitosan, (b) methyl addition, (c) alcohol addition, (d) chlorine addition, (e) cyclohexane addition, (f) benzene addition, and (g) phthalate addition. 


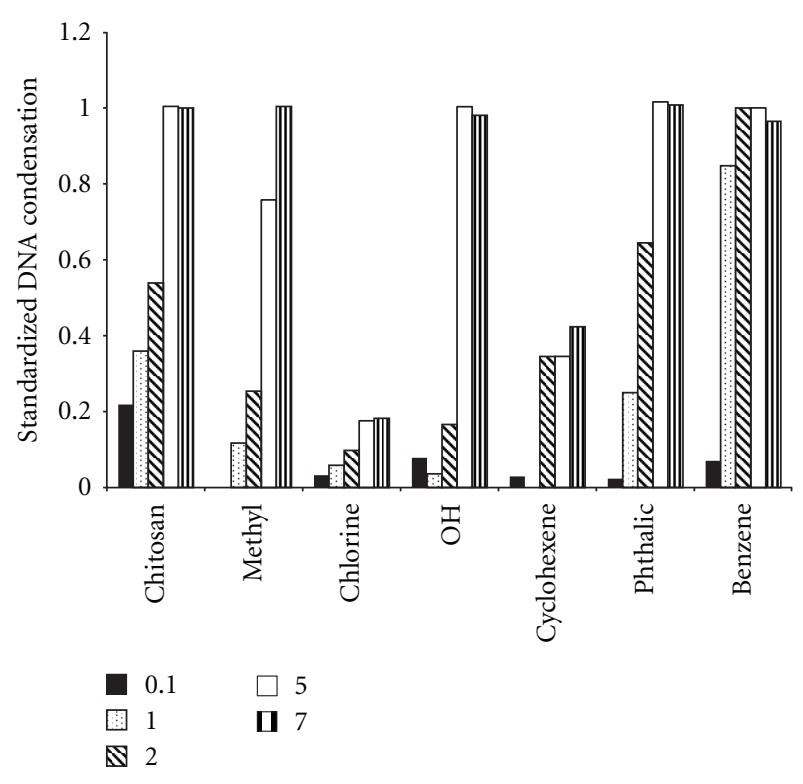

Figure 4: Plasmid DNA at a concentration of $10 \mu \mathrm{g} / \mathrm{mL}$ was vigorously mixed with an equal volume of modified chitosans in a $\mathrm{pH} 7.4$ buffer to yield various stoichiometric charge ratio of modified chitosans to DNA. In the control, DNA was mixed with buffer, no chitosan present in the reaction system. Upon mixing, the reaction tubes were incubated at room temperature for 60 mins and centrifuged for 90 mins at $4^{\circ} \mathrm{C}$. Addition chitosanDNA complexes were separated by centrifugation. The supernatants were carefully pipetted off, and the pellet in each case was resuspended in intracellular saline. ABS $260 \mathrm{~nm}$ was measured for both the supernatants and pellets. Data was averaged over six independent experiments, with triplicates for each data point within each experiment. A standard error of less than $5 \%$ was obtained for data points reported.

viscosity, $(\eta)$, using the Mark-Houwink-Kuhn-Sakurada equation $(\mathrm{MHKS})^{31}$. The average molecular weight (MW) of chitosan was not found to change appreciably with the various chemical treatments employed in this study.

\section{Analysis of Modifications to Chitosan}

FTIR spectra of various modified chitosans prepared in this study are shown in Figure 3; transmittance spectrum is shown.

8.1. Pure Chitosan FTIR. First, an infrared spectrum of pure, underivatized chitosan was taken as a base measurement for comparison with modified chitosan products. The spectrum shows very strong peaks related to the alcohol groups which are centered at $3500 \mathrm{~cm}^{-1}$, carbon-hydrogen bonds centered at $2750 \mathrm{~cm}^{-1}$. A broad peak which stretches between 1000 and $1450 \mathrm{~cm}^{-1}$ is more than likely a combination of different bonds including amines, alcohols, and carboncarbon bonding.

8.2. Methyl Addition to Chitosan FTIR. The spectrum of the methyl addition to chitosan reaction product contained many of the strong peaks observed in the spectrum of pure chitosan, also contained three new peaks centered at approximately 3970,3740 , and $405 \mathrm{~cm}^{-1}$, with the peak at $3740 \mathrm{~cm}^{-1}$ being the most well defined. The peaks at 3970 and $3740 \mathrm{~cm}^{-1}$ are most likely related to the new amine bonds being formed. The peak at $405 \mathrm{~cm}^{-1}$ is difficult to assign due to position within the fingerprint region of an infrared spectrum.

8.3. Alcohol Addition to Chitosan FTIR. The spectrum the alcohol addition to chitosan reaction product contained a much different spectrum from that of the original chitosan. In this spectrum, the two large peaks at 3500 and $2750 \mathrm{~cm}^{-1}$ have been merged into a single broad peak. This characteristic is normally contributed to an increase in alcohol groups.

8.4. Chlorine Addition to Chitosan FTIR. The spectrum of the chlorine addition to chitosan reaction product contained two new peaks of interest in addition to the peaks from the original chitosan sample. New peaks were observed at 3740 and $715 \mathrm{~cm}^{-1}$. These peaks were assigned as the secondary nitrogen group formed and an organic halogen, respectively.

8.5. Cyclohexane Addition to Chitosan. The sample of the cyclohexane addition to chitosan reaction product under standard conditions was too concentrated to take a proper spectrum, instead the mass percent of the sample had to be reduced by a factor of 5 . A new peak was located at $3740 \mathrm{~cm}^{-1}$ which suggests a secondary nitrogen. Another new peak can be seen at $1490 \mathrm{~cm}^{-1}$. This peak actually becomes merged into the large group of peaks between 1450 and $1000 \mathrm{~cm}^{-1}$ which can be seen in pure chitosan spectra. This new peak can be assigned to the large number of saturated aliphatic carbons found within the cyclohexane ring.

8.6. Benzene Addition to Chitosan. The spectrum of the benzene addition to chitosan reaction product did not include new peaks but instead showed a significant increase in the area between the peaks at 2750 and $3400 \mathrm{~cm}^{-1}$. In addition, there is separation of the peaks that occurs between $1000 \mathrm{~cm}^{-1}$ and $1400 \mathrm{~cm}^{-1}$ with the greatest increase occurring at $1100 \mathrm{~cm}^{-1}$. These increases occur in the areas at which a mono substituted benzene would occur.

8.7. Phthalate Addition to Chitosan. Two new peaks can be found in the spectra of the phthalate group addition to chitosan reaction product at 3745 and $1770 \mathrm{~cm}^{-1}$ as well as significant broadening of the peak centered at $3500 \mathrm{~cm}^{-1}$ and the large mass of peaks between 1310 and $1020 \mathrm{~cm}^{-1}$. The new peak at $3745 \mathrm{~cm}^{-1}$ is due to the modification of the nitrogen group. The tertiary nitrogen is also the cause for the broadening of the mass of peaks between 1310 and $1020 \mathrm{~cm}^{-1}$. The peak at 1770 as well as the broadening that is occurring at $3500 \mathrm{~cm}^{-1}$ is due to the ester groups which compose phthalate compounds. 


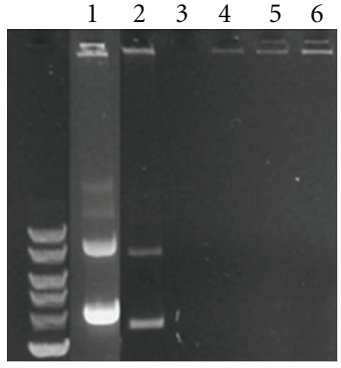

(a)

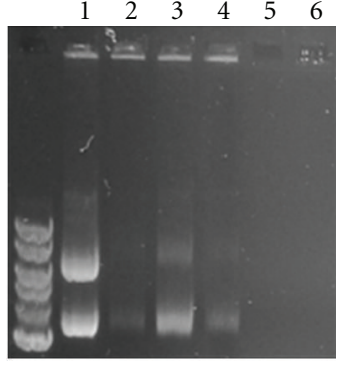

(b)

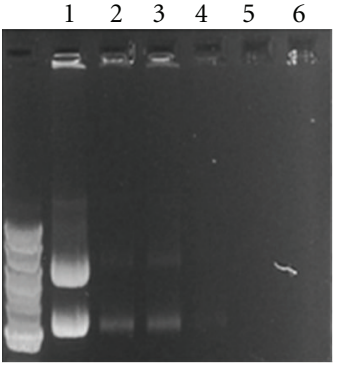

(c)

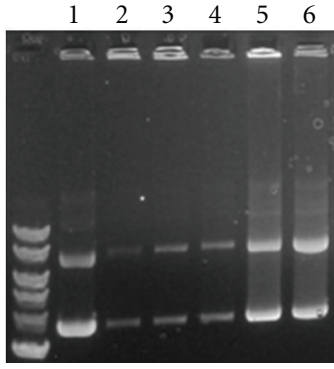

(d)

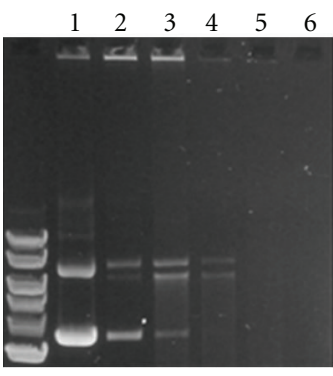

(e)

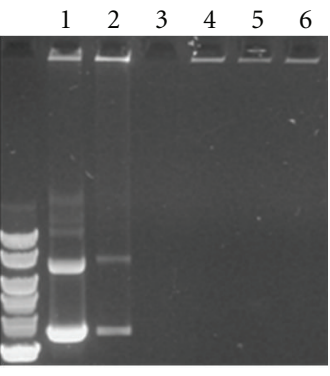

(f)

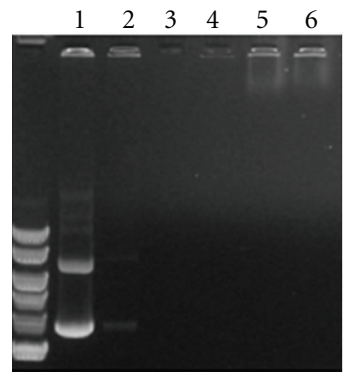

(g)

Figure 5: Mobility of DNA complexed in modified chitosan condensates. Frame (a) is pure chitosan, Frame (b) is methyl-modified chitosan, Frame (c) is alcohol-modified chitosan, Frame (d) is chlorine-modified chitosan, Frame (e) is cyclohexane-modified chitosan, Frame (f) is benzene-modified chitosan, Frame ( $\mathrm{g}$ ) is phthalate-modified chitosan. For all frames, Lane 1 is uncomplexed DNA; Lane 2 is a $0.1 \mathrm{~N}$ : $\mathrm{P}$ ratio. Lane 3, $1 \mathrm{~N}$ : P; Lane 4, $2 \mathrm{~N}$ : P; Lane 5, $5 \mathrm{~N}$ : P; Lane 6, $7 \mathrm{~N}: \mathrm{P}$.

\section{Quantitative Analysis of Chitosan Modifications by Ninhydrin}

Serial dilutions of each modified product and unmodified chitosan were prepared in acetic acid and reacted with ninhydrin. Upon heating, ninhydrin was expected to primarily react with the primary amine groups. Bonded ninhydrin produces a color change within the solution which can be measured by UV-Vis spectroscopy. The sample absorbance is plotted as a function of the concentration of modified chitosan in the solution. Using a linear regression tool, the percent modification can be calculated by the slope of the line for the sample divided by the slope of the line for the absorbance of a solution using D-glucoseamine, a sugar with the same structure as chitosan with only the primary amine present, Table 1 . The substitution of chlorine gave the lowest conversion at $66 \%$, while all other modifications proceeded at over $93 \%$ conversion.

\section{Condensates Production and Characterization Condensation Experiments}

Products from the chemical modifications and pure chitosan were mixed with plasmid DNA to condense condensates using nitrogen to phosphate ratios $(\mathrm{N}: \mathrm{P})$ of $0.1,1,2,5$, and 7. In each case $10 \mu \mathrm{g}$ of DNA was used. The particles were separated by centrifugation and the supernatant solution was analyzed for DNA concentration using PicoGreen fluorescent dye. The quantity of DNA condensed was calculated by the mass balance and standardized to pure sodium acetate solution with no DNA and sodium acetate solution with $10 \mu \mathrm{g}$ of DNA. Figure 4 shows the normalized amount of DNA condensed as a function of N/P ratio, for each of the reaction schemes studied.

Most of the substituted chitosans prepared in this study were able to yield near quantitative condensation efficiencies at a N/P ratio of 5 or greater. However, chlorine and cyclohexane substituted chitosan polymer was uneffective in inducing condensation at the N/P ratios studied. Benzene and phthalic acid substituted chitosans were able to yield a higher condensation efficiency and yield at lower N/P ratios studied.

10.1. Electrophoresis of Condensates. Electrophoresis was used to determine any change in the electrophoretic mobility of complexed DNA. Condensates were created at an $\mathrm{N}: \mathrm{P}$ ratio of $0.1,1,2,5$, and 7 for pure chitosan and all chitosan modification products. The DNA used in these experiments had two fragments and can be seen as a doublet after electrophoresis. In many cases, bands can be seen in lanes with condensed DNA, these bands are most likely caused by partially condensed DNA or DNA which has been released postcondensation. A $0.5 \%$ agarose gel was used so that low mobility would not be an effect of high agarose content. Agarose gels, Figure 5, were developed by UV irradiation of an incorporated ethidium bromide stain. The concentration 
TABLE 1: Slope and conversion based upon quantitative analysis by ninhydrin.

\begin{tabular}{lccccccc}
\hline & \multicolumn{2}{c}{ Control } & \multicolumn{5}{c}{ Chitosan modifications } \\
& D-Glucose amine & Methyl & Alcohol & Chlorine & Cyclo hexane & Benzene & Phthalate \\
\hline Slope & 1.53 & 0.00 & 0.03 & 0.53 & 0.04 & 0.11 & -0.01 \\
\hline Conversion & & 1.00 & 0.98 & 0.66 & 0.98 & 0.93 & 1.01 \\
\hline
\end{tabular}

of the DNA molecular weight standard was equal to that of the samples prior to condensation.

10.2. Zeta Potential of Condensates. The zeta potential analysis of condensed DNA was used to determine the degree to which the polymer charge neutralized the phosphate backbone DNA, and the values are listed in Table 2. The values are the means of between 3 and 5 samples dependant on the variability of the observed values.

\section{Discussion}

Previous study has evaluated, in detail, the ability of various chitosans with varying degrees of acetylation (DA) and degree of polymerization (DP) to compact plasmid and linear DNA [22]. The amount of chitosan required to fully condense DNA was found to be dependent upon the chitosan molecular weight, hence the total charge at a given DA. Thus we have chosen to work with chitosan biopolymer with a MW of $217 \mathrm{kDa}$ and a DA of $81.7 \%$, to obtain effective condensation at medium to low concentrations of chitosan. The goal of this study was to evaluate the effects of electron donation and steric hindrance on the ability of chitosan to condense DNA into a chitosan_DNA complex. To evaluate these properties, different functional groups were chemical substituted onto the primary nitrogen of chitosan, as detailed in Figures 1 and 2. These functional groups were chosen based upon two factors. First, reactions would have to be in high yield. This aspect is of importance because most of the reactions occur on the interface of the solid phase and liquid phase, which in general decreases the degree of substitution. Second, the functional groups should be of similar size within their grouping, so that unbiased observations and conclusions could be made.

The experiments were conducted under the hypothesis that the addition of electron donator groups would help to stabilize the nitrogen in its protonated form $\left(\mathrm{R}-\mathrm{NH}_{3}{ }^{+}\right)$. It is hypothesized that the protonated form of chitosan is needed to create the ionic attraction that occurs between the nitrogen of chitosan and negatively charged phosphate groups of DNA which ultimately forms the nanoparticle. By stabilizing this protonated form, more nitrogen atoms should exist in the charged form, leading to a greater number of bonds or interactions with the phosphate backbone in the DNA molecule. The increase in ionic bonds should mean that DNA should be completely condensed at a lower nitrogen to phosphate ratio. Also the stabilization should show an increase in the effective zeta potential, since the zeta
TABLE 2: Mean zeta potential of condensed DNA particles formed using modified polymers and the standard deviation associated with the measurements.

\begin{tabular}{lcc}
\hline & $\begin{array}{c}\text { Zeta potential } \\
\text { Condensing agent }\end{array}$ & Std Dev \\
\hline Chitosan, pure & -0.64 & 1.0 \\
Methyl addition & 0.00 & 0.0 \\
Alcohol addition & -2.59 & 2.29 \\
Chlorine addition & -25.49 & 3.3 \\
Cyclohexane addition & -3.20 & 4.6 \\
Benzene addition & -5.21 & 3.0 \\
Phthalic addition & -23.46 & 16.7 \\
\hline
\end{tabular}

potential should also be related to the number of ionic bonds occurring between the polymer and DNA.

In contrast, chitosan modified with electron-withdrawing groups should show a lower bonding efficiency, if bonding can even occur. Chemically bonding electronwithdrawing groups to nitrogen is a common method in organic chemistry to protect or deactivate the reactivity of nitrogens within a compound. If the nitrogen groups of the polymer are fully protected, protonation and ultimately the ionic bonding to the phosphate groups of DNA are not likely to occur. Because of this decrease in intermolecular interactions, the zeta potential should be smaller or negative on any particles that do form.

Steric hindrance should also have an effect on the ability of the nitrogen from chitosan to bond to phosphate groups of DNA. By extending the distance between the two charged groups, this ionic bonding is weakened. The weakening of the bonding should decrease the efficiency of the condensation while increasing the zeta potential.

In the present study, the modifications to chitosan proceeded at a very high rate of substitution. The most misleading result from this section is the degree of substitution for the chlorine addition being lower than the two reactions using boronation in which the chlorine modification is a step. It is important to realize that because of the nature of chlorine as a leaving group and especially given the decay that can be physically seen over time that the results are reasonable for reactions that would be occurring simultaneously. The degree of substitution for the chlorine addition might also be influenced by the temperature that the ninhydrin reaction occurs at, which could also increase the degradation rate, releasing chlorine and producing error in the reading. 


\section{Particle Condensation and Characterization}

It is important to note that the production of condensates was not optimized in this study. All other factors, such as temperature, salt concentration, $\mathrm{pH}$, and mixing times were kept constant between experiments. The $\mathrm{pH}$ was specifically maintained near neutral so as to not artificially increase the charge density of the polymers.

All modified polymers were able to precipitate DNA; however, the efficiency was dependant on the modification. Efficiency for the purpose of this topic will be defined as the percent of DNA precipitated by a polymer at a certain nitrogen to phosphate $(\mathrm{N}: \mathrm{P})$ ratio. Previously reported work has noted the transfection efficiency to be optimal when condensates were prepared at an N:P ratio of 5.6:1 [35]. More important than the actual number is the proposed theory that by needing a greater number of polymer subunits, more nonspecific binding occurs. Only two modified polymers were able to precipitate DNA at the same or greater efficiency as bare chitosan, the addition of benzene and phthalate. Benzene-modified chitosan was able to precipitate nearly $85 \%$ of the DNA present at an $\mathrm{N}: \mathrm{P}$ ratio of 1 . At that same ratio, bare chitosan could only precipitate $36 \%$ of present DNA. For all $\mathrm{N}: \mathrm{P}$ ratios greater than 1, benzene-modified chitosan was able to precipitate all DNA present. Chitosan was able to fully precipitate present DNA at $\mathrm{N}: \mathrm{P}$ ratios of 5 and 7. Only phthalate and alcohol-modified chitosan could match this efficiency with that of the alcohol modified chitosan dropping significantly at lower ratios.

In contrast, very slight modifications such as the methyl addition could have a large effect in the precipitation efficiency. Neutral charge group modification showed a drop in efficiency with methyl-modified chitosan only able to fully precipitate present DNA at an $\mathrm{N}: \mathrm{P}$ ratio of 7 . Cyclohexanemodified chitosan at an $\mathrm{N}: \mathrm{P}$ ratio of 7 could only precipitate $42 \%$ of present DNA. The least efficient modification for precipitation was the chlorine addition to chitosan. Chlorinemodified chitosan could only precipitate $18 \%$ of present DNA at an $N: P$ ratio of 7 , less than the $21 \%$ of precipitated DNA for bare chitosan at an $\mathrm{N}$ : $\mathrm{P}$ ratio of 0.1 .

The data from the precipitations correlated well with the gels from the mobility studies. As described in the methods section, the DNA was precipitated at different $\mathrm{N}: \mathrm{P}$ ratios and separated by centrifugation from uncondensed DNA. The condensates that were formed were resuspended into solution and separated by electrophoresis. While DNA bands were seen in condensates created from the modified polymers and bare chitosan at an $\mathrm{N}: \mathrm{P}$ ratio of 0.1 ; bands from other ratios were only seen in polymers which were less efficient. For example, only a very faint band was seen in the gel for condensates created using phthalate-modified chitosan and benzene-modified chitosan, where as bands were seen in all lanes of chlorine-modified chitosan and cyclohexane-modified chitosan. The most interesting result from this study may be in the alcohol-modified chitosan gel. In this experiment, bands can be seen in the lanes corresponding $0.1,1$ and slightly in the lane corresponding to $2 \mathrm{~N}$ : $\mathrm{P}$ ratios; however, no bands can be seen in the higher ratios. This phenomena can be used as a secondary method of determining efficiency as it is most likely caused by weakly condensed DNA.

Another interesting result is that the polymer which hypothetically should have been the least efficient at precipitating DNA, phthalate addition to chitosan, was actually just as efficient at an $\mathrm{N}: \mathrm{P}$ ratios of 5 and 7 or more so at a ratio of 2 than bare chitosan. This effect could be caused by the oxygen groups on the phthalate group forming hydrogen bonds to the DNA as opposed to the ionic-type bonding normally occurring with polycationic polymers. This theory is supported by data reported elsewhere [36] which showed a thermodynamic link between hydrogen bonds forming the condensates.

Finally, the sizes of the chitosan-DNA complexes were analyzed by Dynamic Light Scattering (DLS) using DP801 instrument by Protein solutions Inc. using a calibration with latex standards (spheres) of 21 to $300 \mathrm{~nm}$ in diameter. Our results with light scattering indicate the size of DNA condensates to be about $140-160 \mathrm{~nm}$. These condensates appear to stable as judged by the size from DLS (DLS readings were taken over a period of 3-4 days).

\section{Zeta Potential}

The zeta potential was strongly influenced by the type of modified polymer used for precipitation. Chitosans substituted with an electron-withdrawing group produced particles with strongly negative charges. This data would seem to influence the idea that the precipitation is based upon the hydrogen bonding as opposed to ionic interaction which would produce particles which are charge neutralized. All other modified polymers and bare chitosan produced particles with the zeta potential near zero. This lack of influence on the zeta potential could be a likely result of experimental procedure in which the samples are prepared in a neutral solution. The overall use of negatively charged condensates is still debated, many researchers believe that to be able to transfect through a cell membrane the zeta potential must be positive and transfection efficiency is increased as the magnitude of the potential increases [20] while other studies have shown successful transport of negatively charged particles $[37,38]$. These results should instead be interpreted as the need for hydrogen bonding as a secondary source of binding for efficient polymer carriers.

\section{Conclusions}

Polymer design and modification for the production of condensates is a field which will continue to be strong during the development of gene therapy. With in this field, chitosan has been shown to be useful because of biological and chemical properties. The study has also shown that the efficiency of chitosan to create condensates can be increased through targeted chemical modifications via nucleophilic reactions. The increase in efficiency caused by the modification has been shown to be related to two different factors, electron donation and hydrogen bonding. These factors were shown to also affect the zeta potential. In contrast, this study also 
showed that neutral modifications produce condensates at a significantly lower efficiency. Finally the study showed that steric hindrance has very little effect on the formation and particle size of condensates. Work in progress also includes characterizing the shape and dimensions of the structures formed.

\section{References}

[1] A. V. Il'ina and V. P. Varlamov, "[Chitosan-based polyelectrolyte complexes: a review]," Prikladnaia Biokhimiia i Mikrobiologiia, vol. 41, no. 1, pp. 9-16, 2005.

[2] A. Bhatnagar and M. Sillanpää, "Applications of chitinand chitosan-derivatives for the detoxification of water and wastewater-a short review," Advances in Colloid and Interface Science, vol. 152, no. 1-2, pp. 26-38, 2009.

[3] M. N. V. R. Kumar, R. A. A. Muzzarelli, C. Muzzarelli, H. Sashiwa, and A. J. Domb, "Chitosan chemistry and pharmaceutical perspectives," Chemical Reviews, vol. 104, no. 12, pp. 6017-6084, 2004.

[4] M. Prabaharan, "Review paper: chitosan derivatives as promising materials for controlled drug delivery," Journal of Biomaterials Applications, vol. 23, no. 1, pp. 5-36, 2008.

[5] M. R. Kasaai, "Various methods for determination of the degree of N-acetylation of chitin and chitosan: a review," Journal of Agricultural and Food Chemistry, vol. 57, no. 5, pp. 1667-1676, 2009.

[6] M. Köping-Höggård, I. Tubulekas, H. Guan et al., "Chitosan as a nonviral gene delivery system. Structure-property relationships and characteristics compared with polyethylenimine in vitro and after lung administration in vivo," Gene Therapy, vol. 8, no. 14, pp. 1108-1121, 2001.

[7] R. Jayakumar, M. Prabaharan, S. V. Nair, and H. Tamura, "Novel chitin and chitosan nanofibers in biomedical applications," Biotechnology Advances, vol. 28, no. 1, pp. 142-150, 2010.

[8] R. Jayakumar, N. Selvamurugan, S. V. Nair, S. Tokura, and H. Tamura, "Preparative methods of phosphorylated chitin and chitosan-An overview," International Journal of Biological Macromolecules, vol. 43, no. 3, pp. 221-225, 2008.

[9] K. Yamada, T. Chen, G. Kumar, O. Vesnovsky, L. D. Timmie Topoleski, and G. F. Payne, "Chitosan based water-resistant adhesive. Analogy to mussel glue," Biomacromolecules, vol. 1, no. 2, pp. 252-258, 2000.

[10] R. Vazquez-Duhalt, R. Tinoco, P. D’Antonio, L. D. Timmie Topoleski, and G. F. Payne, "Enzyme conjugation to the polysaccharide chitosan: smart biocatalysts and biocatalytic hydrogels," Bioconjugate Chemistry, vol. 12, no. 2, pp. 301-306, 2001.

[11] L. Q. Wu, H. D. Embree, B. M. Balgley, P. J. Smith, and G. F. Payne, "Utilizing renewable resources to create functional polymers: chitosan-based associative thickener," Environmental Science and Technology, vol. 36, no. 15, pp. 3446-3454, 2002.

[12] C. M. Aberg, T. Chen, A. Olumide, S. R. Raghavan, and G. F. Payne, "Enzymatic grafting of peptides from casein hydrolysate to chitosan. Potential for value-added byproducts from food-processing wastes," Journal of Agricultural and Food Chemistry, vol. 52, no. 4, pp. 788-793, 2004.

[13] H. Yi, L. Q. Wu, W. E. Bentley et al., "Biofabrication with chitosan," Biomacromolecules, vol. 6, no. 6, pp. 2881-2894, 2005.
[14] T. H. Kim, H. L. Jiang, J. W. Nah, M. H. Cho, T. Akaike, and C. S. Cho, "Receptor-mediated gene delivery using chemically modified chitosan," Biomedical Materials, vol. 2, no. 3, article no. S02, pp. S95-S100, 2007.

[15] S. T. Koev, P. H. Dykstra, X. Luo et al., "Chitosan: an integrative biomaterial for lab-on-a-chip devices," Lab on a Chip, vol. 10, no. 22, pp. 3026-3042, 2010.

[16] J. Malmo, K. M. Varum et al., "Effect of chitosan chain architecture on gene delivery: comparison of self-branched and linear chitosans," Biomacromolecules, vol. 12, no. 3, pp. 721-729, 2011.

[17] H. Q. Mao, K. Roy, V. L. Troung-Le et al., "Chitosan-DNA nanoparticles as gene carriers: synthesis, characterization and transfection efficiency," Journal of Controlled Release, vol. 70, no. 3, pp. 399-421, 2001.

[18] S. P. Strand, M. M. Issa, B. E. Christensen, K. M. Vårum, and P. Artursson, "Tailoring of chitosans for gene delivery: novel self-branched glycosylated chitosan oligomers with improved functional properties," Biomacromolecules, vol. 9, no. 11, pp. 3268-3276, 2008.

[19] V. B. Morris, S. Neethu et al., "Studies on the condensation of depolymerized chitosans with DNA for preparing chitosanDNA nanoparticles for gene delivery applications," Journal of Biomedical Materials Research Part B, vol. 89, no. 2, pp. 282292, 2009.

[20] A. V. Kabanov and V. A. Kabanov, "DNA complexes with polycations for the delivery of genetic material into cells," Bioconjugate Chemistry, vol. 6, no. 1, pp. 7-20, 1995.

[21] Y. H. Kim, S. H. Gihm, C. R. Park et al., "Structural characteristics of size-controlled self-aggregates of deoxycholic acidmodified chitosan and their application as a DNA delivery carrier," Bioconjugate Chemistry, vol. 12, no. 6, pp. 932-938, 2001.

[22] S. Danielsen, K. M. Vårum, and B. T. Stokke, "Structural analysis of chitosan mediated DNA condensation by AFM: influence of chitosan molecular parameters," Biomacromolecules, vol. 5, no. 3, pp. 928-936, 2004.

[23] S. P. Strand, S. Danielsen, B. E. Christensen, and K. M. Vårum, "Influence of chitosan structure on the formation and stability of DNA-chitosan polyelectrolyte complexes," Biomacromolecules, vol. 6, no. 6, pp. 3357-3366, 2005.

[24] K. Corsi, F. Chellat, L. Yahia, and J. C. Fernandes, "Mesenchymal stem cells, MG63 and HEK293 transfection using chitosan-DNA nanoparticles," Biomaterials, vol. 24, no. 7, pp. 1255-1264, 2003.

[25] S. Mansouri, P. Lavigne, K. Corsi, M. Benderdour, E. Beaumont, and J. C. Fernandes, "Chitosan-DNA nanoparticles as non-viral vectors in gene therapy: strategies to improve transfection efficacy," European Journal of Pharmaceutics and Biopharmaceutics, vol. 57, no. 1, pp. 1-8, 2004.

[26] T. Kiang, C. Bright, C. Y. Cheung, P. S. Stayton, A. S. Hoffman, and K. W. Leong, "Formulation of chitosan-DNA nanoparticles with poly(propyl acrylic acid) enhances gene expression," Journal of Biomaterials Science, vol. 15, no. 11, pp. 1405-1421, 2004.

[27] T. Kiang, J. Wen, H. W. Lim, and K. W. Leong, "The effect of the degree of chitosan deacetylation on the efficiency of gene transfection," Biomaterials, vol. 25, no. 22, pp. 52935301, 2004.

[28] G. Cignarella, S. Villa et al., "Synthesis of a new series of 2,7-diazospiro[3,5]nonan-1-ones, bioisoesteres of antihypertensive and antithrombotic benzo(h)cinnolinones," European Journal of Medicinal Chemistry, vol. 29, pp. 115-120, 1994. 
[29] A. I. Vogel, Vogel's Textbook of Practical Organic Chemistry, John Wiley, New York, NY, USA, 1989.

[30] S. Favreau, L. Lizzani-Cuvelier, M. Loiseau, E. Dunach, and R. Fellous, "Novel synthesis of 3-oxazolines," Tetrahedron Letters, vol. 41, no. 50, pp. 9787-9790, 2000.

[31] G. W. Kabalka and Z. Wang, "Reaction of trialkylboranes with alkylamines: synthesis of dialkylamines," Organometallics, vol. 8, no. 4, pp. 1093-1095, 1989.

[32] S. Ozaki and T. Akihiro, "The chemistry of isocyanic acid and its derivatives. Part V: the oxidative coupling of ethyl carbamate and urea with cyclohexene, tetrahydrofuran, and cyclooctadiene effected by palladium(II) chloride," Bulletin of the Chemical Society of Japan, vol. 51, pp. 3391-3392, 1978.

[33] E. Curotto and F. Aros, "Quantitative determination of chitosan and the percentage of free amino groups," Analytical Biochemistry, vol. 211, no. 2, pp. 240-241, 1993.

[34] K. W. Leong, H. Q. Mao, V. L. Truong-Le, K. Roy, S. M. Walsh, and J. T. August, "DNA-polycation nanospheres as non-viral gene delivery vehicles," Journal of Controlled Release, vol. 53, no. 1-3, pp. 183-193, 1998.

[35] S. Gao, J. Chen, X. Xu et al., "Galactosylated low molecular weight chitosan as DNA carrier for hepatocyte-targeting," International Journal of Pharmaceutics, vol. 255, no. 1-2, pp. 57-68, 2003.

[36] T. Ehtezazi, T. Govender, and S. Stolnik, "Hydrogen bonding and electrostatic interaction contributions to the interaction of a cationic drug with polyaspartic acid," Pharmaceutical Research, vol. 17, no. 7, pp. 871-878, 2000.

[37] J. D. Heck and M. Costa, "Influence of surface charge and dissolution on the selective phagocytosis of potentially carcinogenic particulate metal compounds," Cancer Research, vol. 43, no. 12 I, pp. 5652-5656, 1983.

[38] S. Zaitsev, R. Cartier, O. Vyborov et al., "Polyelectrolyte nanoparticles mediate vascular gene delivery," Pharmaceutical Research, vol. 21, no. 9, pp. 1656-1661, 2004. 


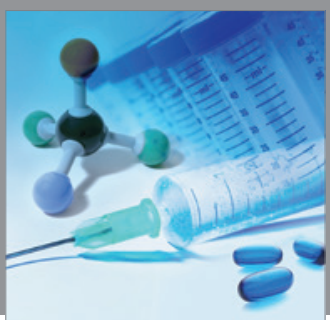

International Journal of

Medicinal Chemistry

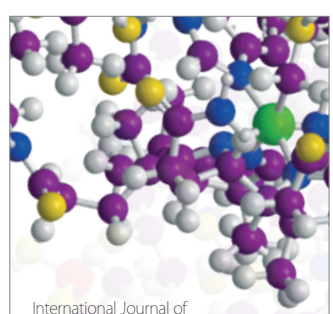

Carbohydrate Chemistry

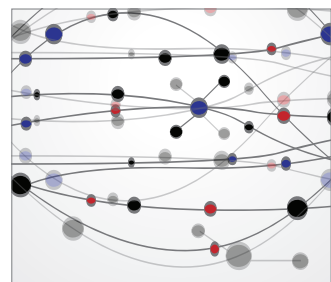

The Scientific World Journal
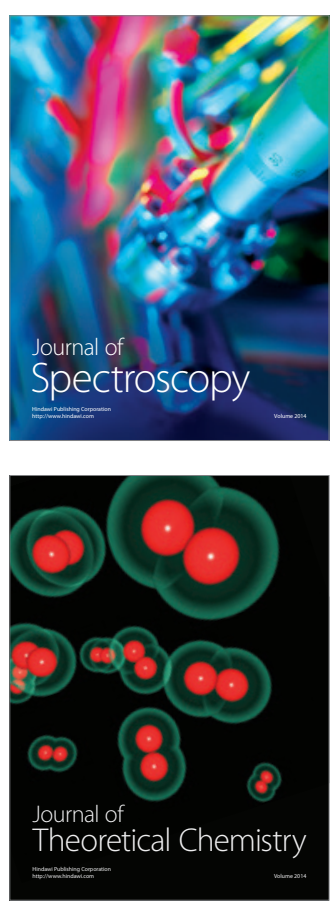
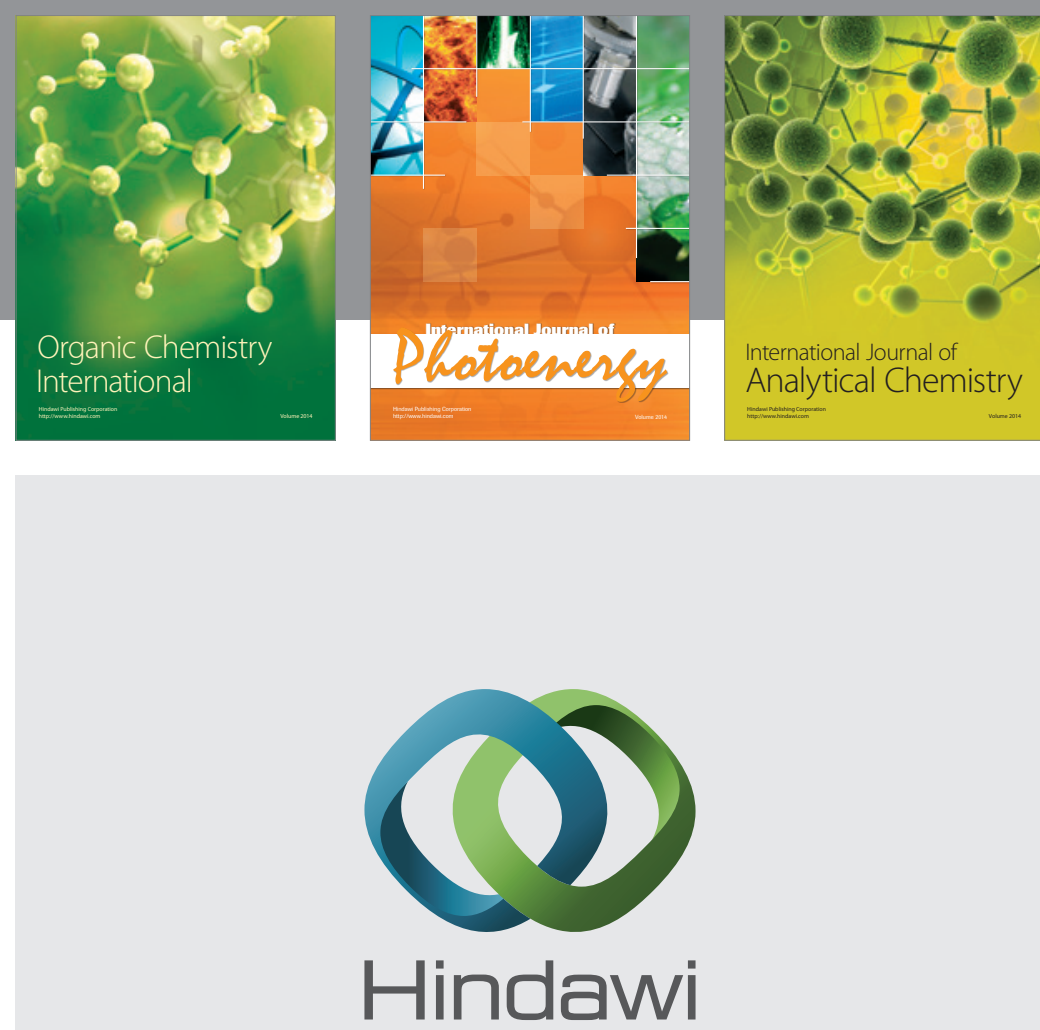

Submit your manuscripts at

http://www.hindawi.com
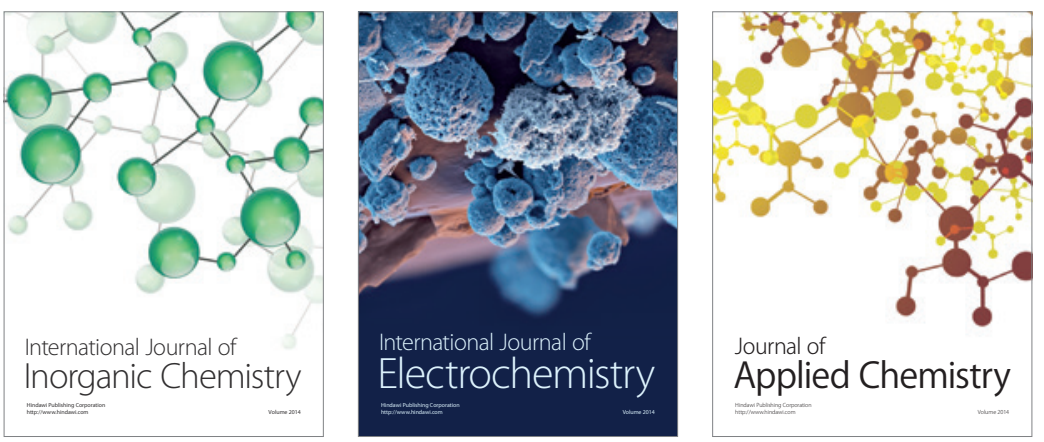

Journal of

Applied Chemistry
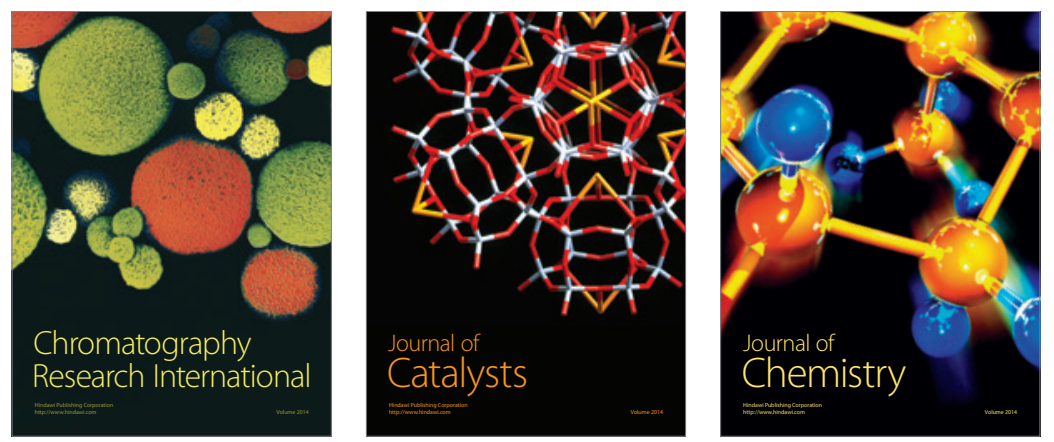
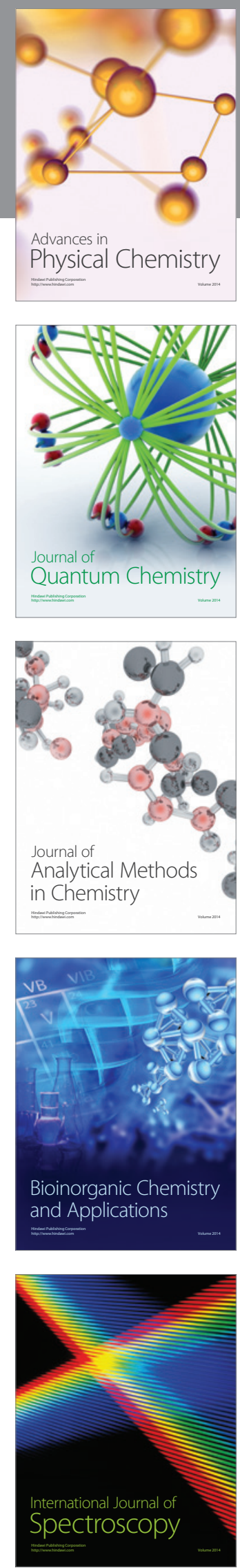